\title{
The Dawn of Literature: Video Games as The New Breed of Modern Popular Literature
}

\author{
Deswandito Dwi Saptanto \\ \{deswanditodwi@unw.ac.id\} \\ English Literature Department, Universitas Ngudi Waluyo \\ Ungaran, Indonesia ${ }^{1}$
}

\begin{abstract}
Video game is a new form of modern popular culture among the people these days. The purpose of this research is to analyze the formula of video games. Writer uses a descriptive qualitative method by analyzing video game using ludology as the discipline, moreover identify narrative and narration along the storyline in video game. This research concludes that video games and storyline bound each other tightly, then creates a thick dramatic form as narrative elements based on the player's decision and choice. This matter as the hint to show that video game is a new form of literary work that is included in the field of modern popular culture. Through video game, a creator creates a special pattern in the process of making a story that gives its users the freedom to explore and engage in stories freely according to their desires and thoughts.
\end{abstract}

Keywords: formula, ludology, narrative, new form of literary work, video games, special patterns

\section{Introduction}

Video games are something that always catches our attention, until now there has been a debate between experts and researchers about the existence of video games, whether video games are a new form of literary work or just a game. The debate about the position of the video game is based on the question of whether 'video games are ruled by narrative elements' or 'how to play the video game'. This study aims to prove that video games are a new form of literary work. Aspects in the video game have put the player as the main character in the storytelling. According to that, the player can feel and carry out the storyline in accordance with the direction of the mission or quest that has been determined by the creator. The concept of the story has been constructed in such a way that the "process of completing' the mission depends on the player's choice.

The freedom of a player to play a video game is a form of interaction between the player - machine - story line. The narrative concept in the video game provides a broad and non-binding boundary that gives players the freedom to complete 
missions or quests according to 'how a player wants to run the story' in the storyline. Ludology or game studies is a suitable approach to analyze this new form of popular culture product. The concept of narration and narrative in the game is also needed to prove 'a video game has a storytelling concept'.

\section{Research Methodology}

\subsection{Qualitative Research}

This research uses a descriptive qualitative method to analyze the object of the study. Using qualitative method is suitable to find, to identify, to reveal and to prove the meaning or the concept of an object of the research.

[1] Lapan stated that research using qualitative methods can reveal social phenomena by using a critical theoretical view.

[2] Taylor revealed that the main purpose of research with qualitative methods is to see, to test and to prove how something is seen from different perspectives.

\subsection{Narrative, Narration and Ludology}

The early appearance of this video game at first only focused on the agility of the player in playing the game. Video games have experienced very fast development, starting from the beginning, namely the game called Pong. Not long after Pong was created, other video games emerged, such as Pac-Man, Tetris, Space Invader, and many other games.

The evolution of video games has grown rapidly so that narrative elements appear in the game, this makes players more interested in following the storyline. This research focuses on video games that have detailed storytelling elements, namely the genre of Role Playing Games (RPG), Open World Games and Simulation games. The presence of the concept of storytelling in video games is a form of narrative developed by game creators. In the concept of storytelling, video games provide a narrative perspective that can be applied directly to the players.

The author certainly concentrates on matters that focus more on social and literary functions. Therefore, this leads to the existence of game studies. Game studies that focus on the humanities are divided into two main factions that have undergone an evolutionary process, namely narratology (narrative and narration) and ludology. Both of these contradict a principle that places whether video games can be studied using narrative theory in general or video games are a genre that must be researched in accordance with its own area.

[3] Barthes states that narrative is carried by articulated language, spoken or written, fixed or moving images, gestures, and the regular mixture of all these substances. Narrative is present in myths, legends, fables, fairy tales, novella, epic, history, tragedy, drama, comedy, pantomime, paintings, news, comics, conversations and many more. Through this diversity of forms, narrative is present in all circumstances and situations. The existence of narratives is present in every age, in every place, in every society. It starts with the history of mankind and there is no person without a narrative. All classes, all cultures, all groups of people, all have their own narratives.

[4] Wolf states that video games are an extension of the concept of drama and narrative, but this has undergone a development and refinement of the 
statement, that video games are alternative semiotic structures called simulation. Although simulations have the same characteristics as narrative (it has the same presence of characters, settings and events), simulations provide fair opportunities for players to carry out the storyline.

In the end, the writer can conclude two things, narrative is the way how the reader sees the complete sequence of the story, while narrative is a process of telling a story and focusing on how to present a story so that it is able to produce specific and chronological things.

[5] [6] Nowadays game studies experts have stated that the existence of narrative is no longer suitable for the form and format of new media. The theory of ludology is a theory that expands the narrative concept to a wider, more flexible, and its position in a work is more straightforward and is not limited to text functions that seem monotonous and insensitive to the times. The concept of narrative is no longer deemed appropriate or compatible to address the forms and formats of new media as technological advances.

[7] Ludology is a scientific analysis that deals with games in general and specifically. Ludology can be defined as a discipline that studies games in general, and video games in particular. The term is not new and it has been previously led in relation with non-electronic Games, particularly among the board tilling community.

Ludologist has stated that to learn a game, the rules of the game must be learned. In the narrative concept, games are seen as a work that feels the same and can be called a new narrative form, so that games can be studied using a narrative concept in general, this is of course contrary to the concept of ludology. Ludology discusses games more as a work whose existence is growing from time to time and must be studied much more specifically and deeply, rather than just studying the concept of basic elements and their forms. The following figure is a schematic of the position of narratology and ludology:

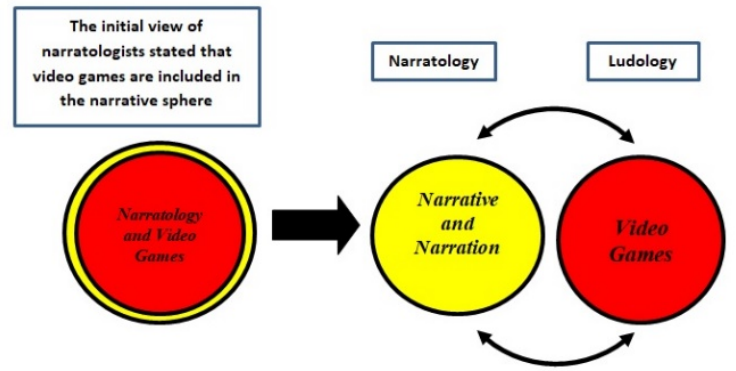

Fig. 1 Scheme of Narratology and Ludology

[8] The basic assumption of narratologists about video games as something that is actually not new but only a development of the concept of the text which they named 'cyberdrama' is completely rejected and becomes a strong debate with ludologists. Ludologists oppose the concept of narratologists that video games are a new concept of a text. Because according to ludologists, in interpreting and conducting research on video games, one must know what games are, what are gameplay, and what are game spaces? 


\subsection{Theory of Adaptation}

A study of adaptation is a study of the process of transformation from one medium to another, from one form to another. The process of transferring this medium used to develop with a simple concept, now it has been transformed into a process that is quite varied. [9] Sapardi Djoko Damono argues that the adaptation is a change or transfer, which of course cannot ignore the shape at all and anyone who wants to explore its ideological aspects cannot help but face the complexity of the form to be dissected. We may never be able to try to make a process of adaptation with one source itself, because in principle, the process of transferring medium of art needs more than one medium.

[10] Seeing an adaptation process means referring to the important elements that an adaptation is seen as: (1) Seen as formal entity or product, which is a process of adaptation, which is a media shift (from novel to film), with the existence of this process means that we can view a work from different points of view and can also create different interpretations. (2) Seen as a process of creation which means an adaptation process always involves 're-interpretation' and 're-creation', this is called an effort to maintain the purity of a work when viewed from various perspectives. (3) Seen from the perspective of its process of reception is a process of adaptation, which is a form of intertext, when a work undergoes an adaptation process, there must be a change / difference between the original context and its transformation.

This research will focus on the study of games and prove that video games are a new form in modern literary works. Adaptation theory is also applied to find the concept and position of games in the realm of literary works.

\section{Finding and Discussion}

The concepts of narratology and ludology were initially different. Narratology is seen video games as a story and ludology is seen video games as something unique. Along with its development, these two elements form a strong structure that produces a new form of literary art with media and packaging, newer and more interesting.

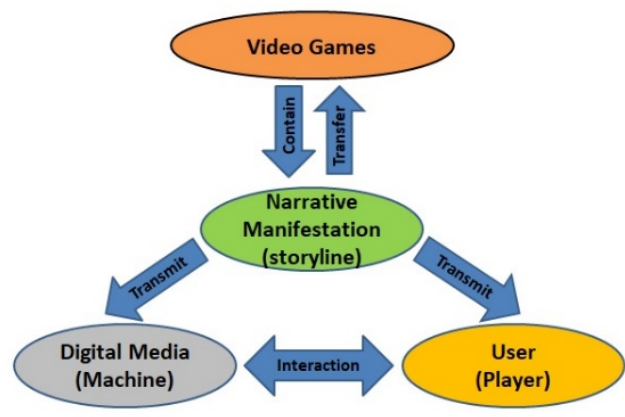

Fig. 2 Scheme of narrative merges with video game

\subsection{Video game as the Product of Adaptation Process}


[11] Jay David Bolter and Richard Grusin in Hutcheon stated that The recent phenomenon of films being 'musicalized' for the stage is obviously economically driven. The movies of The Lion King or The Producers offer readymade name recognition for audiences, relieving some of the anxiety for Broadway producers of expensive musicals. Like sequels and prequels, director's cut, DVDs and spin-offs, videogame adaptations based on films are yet another way of taking one 'property' in a 'franchise'and reusing it in another medium.

These two figures express a theory which they call 'remediation 'which is basically a process of transfering media or it can be called a adaptation. A media transfer must be complete without compromising the essence and detail of the story content that has been created in the previous media.

[12] Context a remediation is with the term 'borrowing' from one medium to another, this can be shown in the transformation process from novel to film as an example. Novel to film is a transitional process which essentially wants to change a work from one medium to another that has a different physical form, the change from novel to film or the process of transferring this medium according to Jay David Bolter and Richard Grusin is something that must be closely watched. Because the changes in the existing media certainly do not change the content that has been created because the content has been borrowed, but the media is not quoted or taken because it is no longer in the same format. The following is a form of representation of the adaptation from novels to video games:
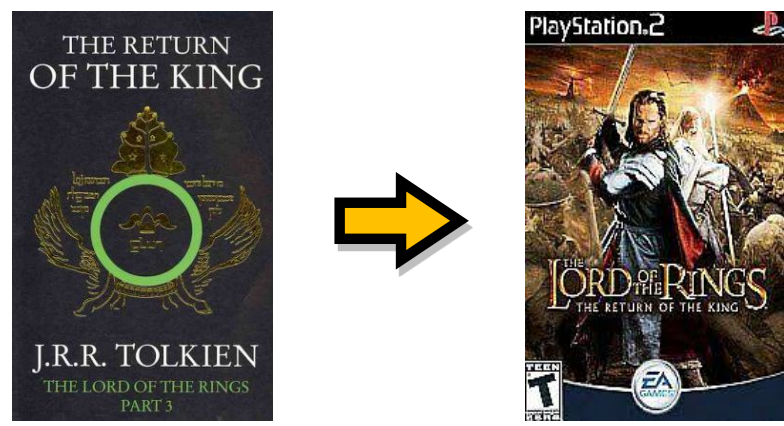

Fig. 3 Depiction of novel adaptation to the video game

\subsection{Video game as a new form of literary work}

The video game has a unique characteristic that actually gives every player a new sensation. Different from the ordinary literary work, the video game puts the author in a secondary place and places player in a first place to explore the storyline.

When we play skyrim as a form of role playing game genre, we can transfer our imagination into a real description into the game using the option called 'character creation'. This option is usually can be accessed in the very beginning of the story. This option give the player opportunities to customize their characters including physical appearance, skill, gear and outfit.

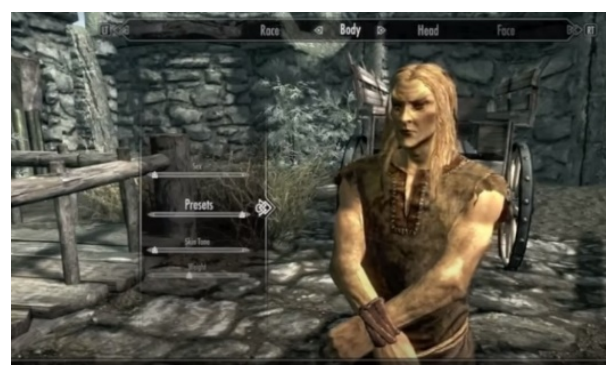


Fig. 4 Character creation in The Elder Scrolls: Skyrim

Talking about role playing games, so we have to concern about the details of the storyline. Role playing games provides various and non-linear mission or quest to be accomplished. Role playing games has also the same characteristic with the open-world game, both of them provides vast area to be explored and a detailed storyline that often divides into many kinds of main quest and side quest. Grand Theft Auto (GTA) is the pioneer of open world game genre. GTA brings a detail storyline in a form of various mission in a thematic and iconic cities in America.

Unlike movies and novels, The assimilation process of narrative elements and digital video in video game gives 'freedom' to the player to accomplish the mission or quest, this is called 'user-driven'. Here is the scheme of the distinction between author-driven and user-driven:

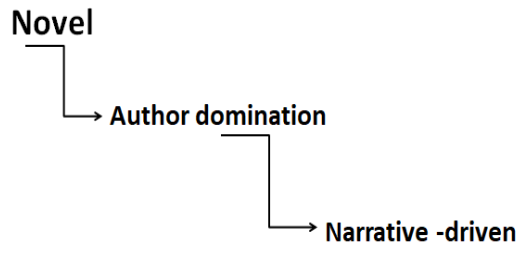

Fig. 5 Scheme of narrative driven

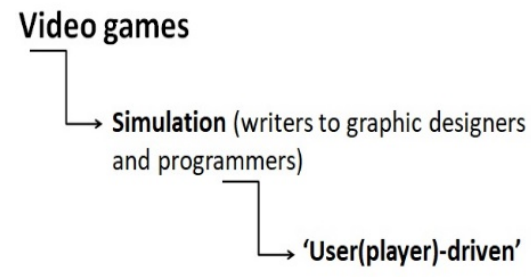

Fig. 6 Scheme of user-driven

The existence of video games as a new form of modern literary work is the evidence of the transformation process of a media transfer from video games to novels. It can happen because the narrative elements in the video game are similar in presentation. The Narrative concept has been assimilated into the form of a simulation concept.

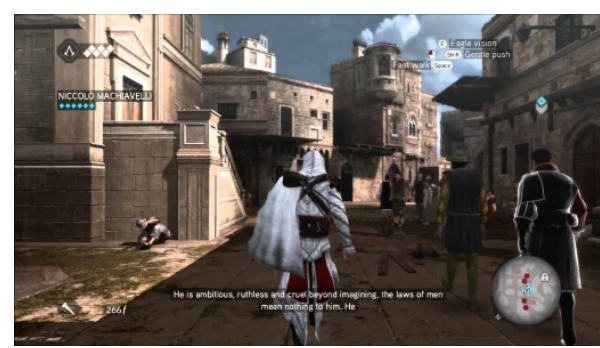




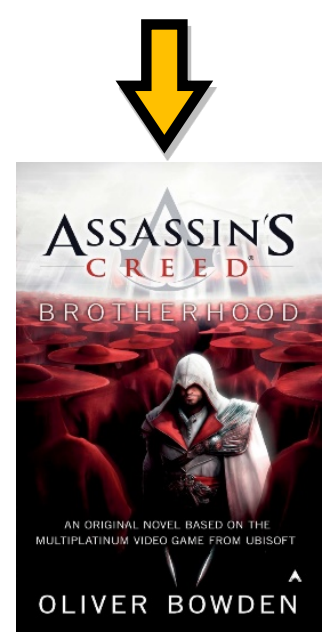

Fig. 7 Depiction of video game adaptation to the novel

\section{Conclusion}

This research has explored the ins and outs of video games, which are a new form of literary work created by the accumulation of narrative elements into digital video games. Video games are electronic games that involve user interface interactions to generate visual feedback on a video device, but moreover video games provide detailed character, events, settings.

The existence of story elements complexity creates a new paradigm of understanding game as the new form of modern literary work and the product of modern popular culture.

Video game can be categorized as: (1) As a result of a process of adaptation which is transferred the work from one media to another media. (2) As a brand new form of modern literature called 'Digital Literature', that can stand alone, since it has a narrative elements in a digital media and provide user-driven

\section{References}

[1] Lapan, S.D. et. Al. Qualitative Research: An Introduction to Methods and Designs. San Francisco: John Wiley \& Sons, Inc; 2012.3.

[2] Taylor, S.J. et. Al. Introduction to Qualitative Research Methods: A Guidebook and Resource. Fourth Edition. New Jersey: John Wiley \& Sons, Inc; 2016.7-8

[3] Barthes, R. Introduction to the Structural Analysis of Narratives. New York: Hill and Wang. 1977.79

[4] Wolf, MJP \& Perron, B. The Video Game: Theaory Reader. New York: Routledge. 2003. 221-222

[5] Juul, J. 2005. Half-Real, Video Games between Real Rules and Fictional Worlds . Cambridge: The MIT Press. In Jakobsson, Mikael. 2007. http://mjson.se/doc/halfreal_review.pdf. 
[6] Simons, J. 2001-2007. \&quot; Narrative, Games , and Theory ". http: // gamestudies. org / 0701 / articles / simons .

[7] Frasca, G. 2003. Simulation versus Narrative. In: Wolf, Mark JP and Perron, Bernard. 2003. The Video Game Theory Reader . New York, Routledge pp. 201 to 235 [8] Walther, Bo Kampmann. 2003. "Playing and Gaming. Reflections and Classifications ", in: Game Studies 3.1, http://www.Gamestudies.org/0301/walther/. [9] Damono, S.D Transfer Wahana . Jakarta: Editum. 2012

[10] [11] Hutcheon, L. A Theory of Adaptation . New York \& London: Routledge Taylor \& Francis Group. 2006.5 